\title{
The effect of an Olympic distance triathlon on the respiratory muscle strength and endurance in triathletes
}

\author{
Alain Boussana ${ }^{1,2, *}$, Olivier Galy ${ }^{3}$ Daniel Le Gallais ${ }^{4}$, Olivier Hue ${ }^{2}$ \\ 'Department Higher Institute of Physical and Sports Education, University Marien Ngouabi, Brazzaville, Congo \\ ${ }^{2}$ Department Sciences and Techniques of Physical and Sports Activities, University Antilles Guyane, Pointe à Pitre Cedex, France \\ ${ }^{3}$ Department Higher School of Professorship and Education, University of New-Caledonia, Noumea CEDEX, New-Caledonia, France \\ ${ }^{4}$ Department Sciences and Techniques of Physical and Sports Activities, University of Montpellier, Montpellier, France
}

High-intensity exercise, marathons, and long distances triathlons have been shown to induce the fatigue of respiratory muscles (RMs). Nevertheless, fatigue and the recovery period have not been studied in response of an Olympic distance triathlon (1.5-km swim, 40-km bike, 10-km run: short-distance triathlon). The aim of this study was to evaluate the RM fatigue induced by an Olympic distance triathlon. Nine male triathletes ( $24 \pm 1.1$ years) underwent spirometric testing and the assessment of RM performance. Respiratory function tests were conducted in sitting position. Spirometric parameters, maximal inspiratory and expiratory pressures, and RM endurance assessed by measuring the time limit were evaluated before (pre-T), after (post-T), and the day following the triathlon (post-T-24 hr). Residual volume increased: pre-T vs. post-T $(P<0.002)$, maximal inspiratory pressure significantly decreased from
$127.4 \pm 17.2$ (pre-T) to $121.6 \pm 18.5 \mathrm{cmH}_{2} \mathrm{O}$ (post- $\left.-\mathrm{T}\right)(P<0.001)$ and returned to the pre-T value $24 \mathrm{hr}$ after the race $(125.0 \pm 18.6)$. RM endurance significantly decreased from 4:51 $\pm 0: 8$ (pre-T) to $3: 13 \pm 0: 7$ min (post-T, $P<$ $0.001)$ and then remained decreased for $24 \mathrm{hr}$ after the race from $4: 51 \pm$ 0:8 (pre-T) to 3:39 $\pm 0: 4 \mathrm{~min} 24 \mathrm{hr}$ after $(P<0.002)$. Both, strength and endurance of inspiratory muscles decrease after Olympic distance triathIon. Furthermore, the impaired of inspiratory muscle endurance $24 \mathrm{hr}$ after the race suggested a slow recovery and persistence of inspiratory muscle fatigue.

Keywords: Maximal inspiratory pressure, Athletic training, Pulmonary function, Inspiratory muscle fatigue, Respiratory muscle time limit

\section{INTRODUCTION}

Respiratory muscle (RM) performance, defined as the capacity of RM to achieve contractile functions, depends on strength and endurance. Inspiratory strength is assessed from the twitch transdiaphragmatic pressures (Walker et al., 2011; Wüthrich et al., 2013). Expiratory strength is assessed from static mouth pressure during maximal expiratory effort $\left(\mathrm{P}_{\mathrm{Emax}}\right)$ (Black and Hyatt, 1969). $\mathrm{RM}$ endurance is assessed from maximal voluntary ventilation (MVV), whereas inspiratory and expiratory muscle endurance are assessed from inspiratory $\left(75 \% \mathrm{P}_{\text {Imax }}\right)$ and expiratory $\left(80 \% \mathrm{P}_{\mathrm{Emax}}\right)$ loaded breathing, respectively, and the measurement of the endurance time limit $\left(\mathrm{T}_{\mathrm{lim}}\right)$, i.e., the length of time before task failure (Perret et al., 1999).
Decreases in transdiaphragmatic pressure (Walker et al., 2011), maximal inspiratory and expiratory pressures $\left(\mathrm{P}_{\operatorname{Imax}}\right.$ and $\left.\mathrm{P}_{\mathrm{Emax}}\right)$ have been well documented after laboratory exercise (Katayama et al., 2012; Verges et al., 2007) and marathon races (Chevrolet et al., 1993; Ross et al., 2008; Tiller et al., 2019). Similarly, MVV and $\mathrm{T}_{\lim }$ for inspiratory muscles were decreased after long-term exhaustive exercise (Bender and Martin, 1985; Boussana et al., 2003) and both $24 \mathrm{hr}$ (Warren et al., 1989) and 3 days (Ker and Schultz, 1996) postultramarathon.

Although RM performance has been studied during a long-distance triathlon $(3.8-\mathrm{km}$ swim, $180-\mathrm{km}$ cycle, and $42.195-\mathrm{km}$ run) (Hill et al., 1991), within 10 min of race completion and on the morning after, it has never been studied after an Olympic triathlon at very high-intensity levels. Recently, Smith et al. (2014)
${ }^{*}$ Corresponding author: Alain Boussana (iD https://orcid.org/0000-0002-5051-0143 Higher Institute of Physical and Sports Education (I.S.E.P.S), University Marien Ngouabi, BP 1100 Brazzaville, Congo

E-mail: bboussan@gmail.com

Received: July 1, 2020 / Accepted: July 17, 2020
This is an Open Access article distributed under the terms of the Creative Commons Attribution Non-Commercial License (https://creativecommons.org/licenses/by-nc/4.0/) which permits unrestricted non-commercial use, distribution, and reproduction in any medium, provided the original work is properly cited. 
and previously, Johnson et al. (1993) reported that exercise at 85\% maximal oxygen uptake $\left(\mathrm{VO}_{2 \max }\right)$ induced fatigue and decreased blood flow in inactive limb. Indeed, in the two above-cited studies, the authors pointed to the intensity $\left(>85 \% \mathrm{VO}_{2 \max }\right.$ ) of the exercise more than the duration as the cause of fatigue on RM. The Olympic distance triathlon is the standard race for the Olympics and World Championships (1.5-km swim, 40-km cycle, 10-km run), it is a heavy-intensity, sustained exercise which could impinge on the capacity of RM. However, the impact and recovery period of a such effort on RM performance in real competition received little attention. RM performance has been shown to be impaired after cycle-run successions in laboratory conditions (Boussana et al., 2001), but never investigated after an Olympic distance triathlon.

As the decreases in RM endurance recover less rapidly than the decreases in RM strength (Ker and Schultz, 1996; Ross et al., 2008), we hypothesised that inspiratory muscle endurance impairment following an Olympic distance triathlon would not be completely reversed $24 \mathrm{hr}$ after the race. To verify this hypothesis, we compared the performance of inspiratory muscle before an Olympic triathlon, after the race, and during the recovery period in highly competitive male triathletes.

\section{MATERIALS AND METHODS}

\section{Participants}

Nine highly competitive male triathletes participated in this experiment. They were $24 \pm 1.1$ years old, weighed $69.0 \pm 1.3 \mathrm{~kg}$, and were $173.1 \pm 1.2 \mathrm{~cm}$ tall. Before participating in this study, participants performed spirometry test and all had normal spirometric parameters: forced expiratory volume in $1 \mathrm{sec}\left(\mathrm{FEV}_{1}\right)$, forced vital capacity (FVC) $>80 \%$, and $\mathrm{FEV}_{1} / \mathrm{FVC}$ ratio $>75 \%$ compared to American Thoracic Society (1986) values. Participants were members of the university athletics team of the University. They trained regularly $16 \pm 2 \mathrm{hr}$ per week and had no respiratory abnormalities or cardiovascular disease. They competed at a national or international level (Table 1). Before participating in this research, they all gave written consent approved by the local ethics committee. The study was in accordance with the Helsinki Declaration.

\section{Procedure}

The study followed a repeated-measures experimental design. The triathletes trained in maximal respiratory manoeuvres as well as the cycloergometer test prior to testing. They performed an in-
Table 1. Anthropometric characteristics, training distances, triathlon time performances of the triathletes

\begin{tabular}{lc}
\hline Variable & Mean \pm SEM \\
\hline No. of subjects & 9 \\
Age (yr) & $24 \pm 1.1$ \\
Height (cm) & $173.1 \pm 1.2$ \\
Weight (kg) & $69 \pm 1.3$ \\
Training distances (km/wk) & \\
Swim & $13.5 \pm 1.9$ \\
Bike & $290 \pm 45.9$ \\
Run & $41.5 \pm 4.2$ \\
Training load (hr/wk) & $16 \pm 2$ \\
Triathlon time performances La Grande Motte (hr/min) & $2: 08 \pm 0: 03$ \\
VO2max (mL/kg/min) & \\
Max & $69.9 \pm 0.9$ \\
Thent & $49.2 \pm 1.8$ \\
HR (b/min) & \\
Max & $179 \pm 2.3$ \\
Thent & $144 \pm 1.8$ \\
\hline
\end{tabular}

SEM, standard error of the mean; $\mathrm{VO}_{2 \max }$, maximal oxygen uptake; $T_{\text {vent, }}$ ventilatory threshold: HR, heart rate.

Training distances were averaged weekly during the study period.

cremental cycle test before entering a three-phase protocol that took place prior to the triathlon, after the race, and $24 \mathrm{hr}$ after the race. An electromagnetic cycle ergometer (Monark 864, MonarkCrescent AB, Varburg, Sweden) was used to perform the incremental test. After a 3-min warm-up at $30 \mathrm{~W}$, the power was then increased by $30 \mathrm{~W}$ every minute until the subject reached volitional fatigue (Galy et al., 2013) and maximal oxygen uptake $\left(\mathrm{VO}_{2 \max }\right)$ and ventilatory threshold $\left(\mathrm{Th}_{\mathrm{vent}}\right)$ was assessed according to conventional criteria (Beaver et al., 1986).

The three phases of the protocol were performed on different days, but always in the afternoon. Phases 1, 2, and 3 each consisted of a spirometric test and measurements of $\mathrm{P}_{\mathrm{Emax}}, \mathrm{P}_{\mathrm{Imax}}$, and RM endurance $\left(\mathrm{T}_{\text {lim }}\right)$. Phase 1 was conducted 2 to 5 days before the triathlon. The participants were required to avoid competition for the week before the triathlon, but daily training was authorized except on the trial day. Phase 2 was conducted 2:00 $\pm 0: 30 \mathrm{hr}$ after the race. The postrace spirometric test, $\mathrm{RM}$ strength, and endurance were performed as rapidly as possible, because that the distance between the race location and the hospital center was 20 $\mathrm{km}$. Phase 3 was conducted 24:00 \pm 3:00 hr after phase 2. All the tests were made in laboratory, in ambient room conditions of 755 $\mathrm{mmHg}, 21^{\circ} \mathrm{C}-22^{\circ} \mathrm{C}$ and $50 \%$ humidity. The Olympic distance triathlon was held at the Grande Motte. The water had a temperature of $14^{\circ} \mathrm{C}$ and the ambient temperature was $18^{\circ} \mathrm{C}$. 


\section{Evaluation of spirometry test and RM strength}

$\mathrm{FEV}_{1}, \mathrm{FVC}$, residual volume (RV), functional residual capacity (FRC), total lung capacity, and maximal expiratory flows were measured by spirometry (Pulmonet III, Sensor Medics, Anaheim, CA, USA) according to standard techniques and procedures. Lung volumes and expiratory flows were compared with reference values (American Thoracic Society, 1986) to ensure that the triathletes had values within the normal range. RM strength i.e., maximal expiratory and inspiratory pressures tests were assessed in the sitting position using the technique of Black and Hyatt (1969). According to this method, triathletes perform tests until three reproducible measurements were obtained and the best value for each athlete was reported (Hayot et al., 2000).

\section{RM endurance}

$\mathrm{RM}$ endurance was measured by assessing the $\mathrm{T}_{\text {lim }}$ with a standardized method using controlled breathing developed by Matecki et al. (2001) and used in previous studies (Boussana et al., 2003; Koechlin et al., 2005). Briefly, $\mathrm{T}_{\text {lim }}$ represents the maximal time a subject can breathe against a predetermined inspiratory submaximal load (Roussos et al., 1979). During the experimental run, a threshold valve was connected to the inspiratory side of the respiratory system, as previously described (Roussos et al., 1979). The measurement of the RM endurance was performed using a threshold inspiratory muscle trainer valve (Threshold Inspiratory Muscle Trainer; Healthscan Products Inc., Cedar Grove, NJ, USA) that allows the imposition of a controllable pressure sensor (Johnson et al., 1996; Zocchi et al., 1993). The time limit of RM is performed at the functional residual capacity against a load of $75 \% \mathrm{P}_{\mathrm{Imax}}$

Table 2. Mean spirometric parameter values measured before (pre-T), after (post- $\mathrm{T}$ ), and $24 \mathrm{hr}$ after triathlon (post-T-24 hr)

\begin{tabular}{lccc}
\hline Parameter & Pre-T & Post-T & Post-T-24 hr \\
\hline FVC (L) & $5.44 \pm 0.7$ & $5.22 \pm 1.1$ & $5.28 \pm 0.9$ \\
$\mathrm{FEV}_{1}(\mathrm{~L})$ & $4.62 \pm 0.7$ & $4.10 \pm 0.8$ & $4.24 \pm 0.7$ \\
$\mathrm{FEV}_{1} / \mathrm{FVC}(\%)$ & $84.8 \pm 4.3$ & $79.0 \pm 3.5$ & $80.6 \pm 1.1$ \\
$\mathrm{RV}(\mathrm{L})$ & $1.94 \pm 0.52$ & $2.58^{*} \pm 0.21$ & $1.99 \pm 0.43$ \\
FRC (L) & $1.86 \pm 0.43$ & $2.33^{*} \pm 0.41$ & $1.89 \pm 0.32$ \\
$\mathrm{FEF}_{25 \%-75 \%}(\mathrm{~L} / \mathrm{sec})$ & $4.75 \pm 1.01$ & $4.20 \pm 1.04$ & $4.32 \pm 0.96$ \\
FEF $_{50 \%}(\mathrm{~L} / \mathrm{sec})$ & $4.71 \pm 1.11$ & $4.75 \pm 1.45$ & $4.69 \pm 1.13$
\end{tabular}

Values are expressed as mean \pm standard deviation.

Pre-T, before triathlon; Post-T, after triathlon; Post-T-24 hr, $24 \mathrm{hr}$ after triathlon; FVC, forced vital capacity; $\mathrm{FEV}_{1}$, forced expiratory volume in $1 \mathrm{sec}$; $F E V_{1} / F V C$, ratio of $\mathrm{FEV}_{1}$ to $\mathrm{FVC}$; $\mathrm{RV}$, residual volume; $\mathrm{FRC}$, functional residual capacity; $\mathrm{FEF}_{25-75 \%}$, mean forced expiratory flow during the middle half of $\mathrm{FVC}$; $\mathrm{FEF}_{50 \%}$, forced expiratory flow rate at $50 \%$ of FVC.

*Significant difference, post-T vs. pre-T and post-T-24 $\mathrm{hr}(P<0.05)$. placed on the inspiratory orifice and imposed on the athlete with each inspiration (Ker and Schultz, 1996). The test is stopped when the subject no longer maintains the target tidal volume for three consecutive breaths or when he releases the mouthpiece. At that moment, it reaches the limit time of respiratory endurance.

\section{Statistical analysis}

The pre-T, post-T, and post-T-24 hr spirometric parameters and $\mathrm{RM}$ performance variables were compared using repeated-measures analysis of variance (ANOVA). Scheffé post hoc test was carried out when significant results were obtained with ANOVA. Statistical significance was set at $P<0.05$. Results are expressed as means \pm standard deviations. Statistical analyses were performed with SYSTAT software.

\section{RESULTS}

The triathletes' general characteristics are presented in Table 1: age, weight, height, training regimens, triathlon time performances ( $2 \mathrm{hr} 08 \pm 0.03 \mathrm{~min}), \mathrm{VO}_{2}$, heart rate values at exhaustion, and $\mathrm{Th}_{\text {vent }}$ of incremental exercise.

\section{Spirometry and RM strength}

The comparison between values for $\mathrm{FEV}_{1}, \mathrm{FVC}, \mathrm{FEV}_{1} / \mathrm{FVC}$, forced expiratory flow $\left(\mathrm{FEF}_{25 \%-75 \%}\right)$ in the middle half and forced expiratory flow rate at $50 \%\left(\mathrm{FEF}_{50 \%}\right)$ before, after and $24 \mathrm{hr}$ after the triathlon remained mostly unchanged. In contrast, RV and FRC increased significantly after compared to before the triathlon $(P<0.002)$ (Table 2). There was no significant change in $\mathrm{P}_{\text {Emax }}$ before $(117.6 \pm$

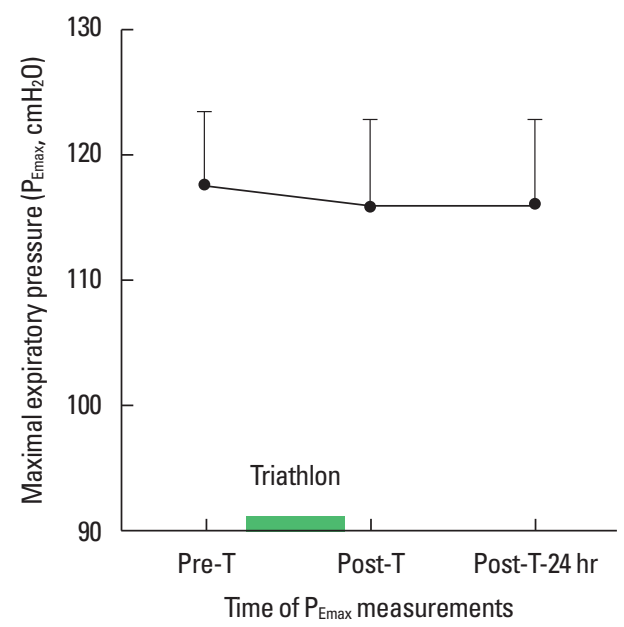

Fig. 1. Maximal expiratory pressure $\left(\mathrm{P}_{\mathrm{Emax}}\right)$ pre-T versus post-T and post-T-24 hr. No significant difference between the two trials. 


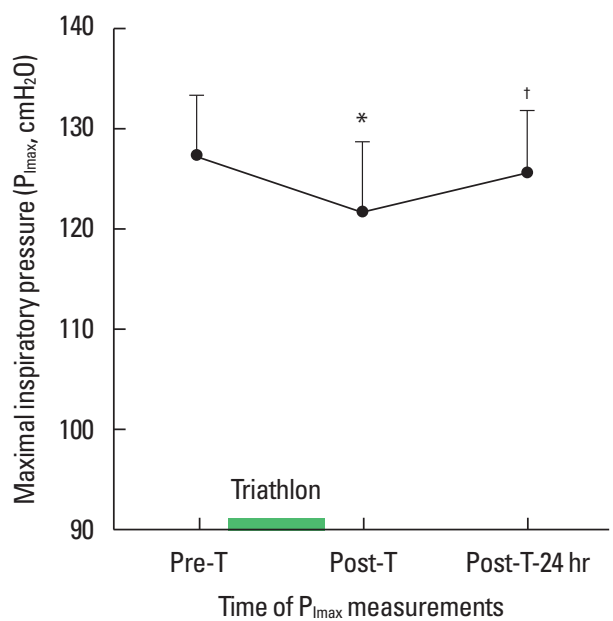

Fig. 2. Maximal inspiratory pressure $\left(P_{\max }\right)$. ${ }^{*}$ Significant $(P<0.05)$ different between pre-T compared to post-T. ${ }^{\dagger}$ Significant $(P<0.05)$ different between post-T compared to post-T-24 hr.

$\left.12.8 \mathrm{cmH}_{2} \mathrm{O}\right)$, after $\left(115.8 \pm 14.1 \mathrm{cmH}_{2} \mathrm{O}\right)$ and $24 \mathrm{hr}$ after the triathlon (116.0 $\pm 14.0 \mathrm{~cm} \mathrm{H}_{2} \mathrm{O}$ ) (Fig. 1). $\mathrm{P}_{\text {Imax }}$ showed a significant $4.5 \%$ decrease from before to after $\left(127.4 \pm 17.2 \mathrm{cmH}_{2} \mathrm{O}\right.$ and $121.6 \pm 18.5 \mathrm{cmH}_{2} \mathrm{O}$, respectively, $P<0.001$ ) but had returned to the baseline value at $24 \mathrm{hr}$ after the triathlon $\left(125.8 \pm 18.6 \mathrm{cmH}_{2} \mathrm{O}\right)$ $(P>0.23)$ (Fig. 2).

\section{RM endurance}

RM endurance $\left(\mathrm{T}_{\text {lim }}\right)$ showed a $30.5 \%$ decrease from pre- $\mathrm{T}$ (4:51 $\pm 0: 8 \mathrm{~min})$ to post-T $(3: 13 \pm 0: 7 \mathrm{~min})(P<0.001)$, and a $24.8 \%$ decrease from pre-T to post-T-24 hr $(3: 39 \pm 0: 4 \mathrm{~min})(P<$ 0.002) (Fig. 3).

\section{DISCUSSION}

The observation of the main results allowed us to conclude that an Olympic distance triathlon induced a 30.5\% decrease in inspiratory muscle endurance in triathletes after the race and that $24 \mathrm{hr}$ later it remained decreased by $24.7 \%$ (Fig. 3). These changes suggest that the inspiratory requirements during an Olympic distance triathlon impaired inspiratory muscle endurance.

The $4.5 \%$ decrease in maximal inspiratory pressure ( $\mathrm{P}_{\text {Imax }}$ : Fig. 2$)$ noted after the Olympic distance triathlon was in line with the $13 \%$ decrease in maximal inspiratory pressure reported after strenuous endurance exercise $\left(85 \% \mathrm{VO}_{2 \max }\right)$ (Smith et al., 2014). To explain these results, these authors assumed that inspiratory muscle fatigue was preferentially due to the high exercise intensity $(>85 \%$ $\left.\mathrm{VO}_{2 \max }\right)$.

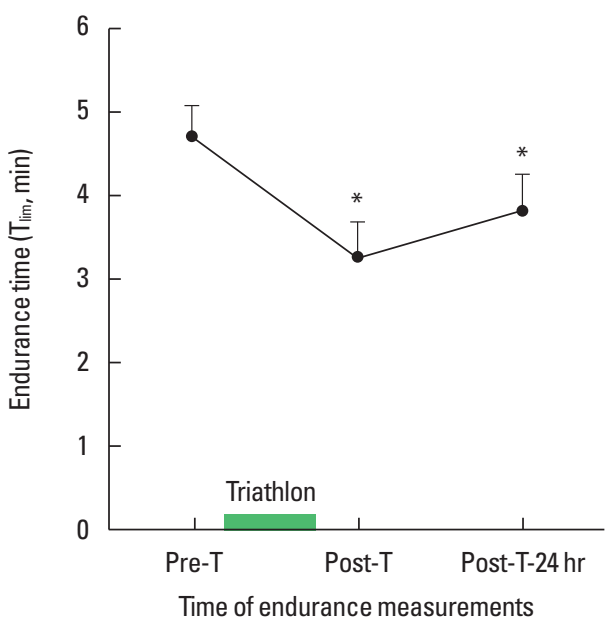

Fig. 3. Respiratory muscle endurance $\left(T_{\text {lim }}\right)$, *Significant $(P<0.05)$ difference between pre-T compared to post-T and post-T-24 hr.

The reduced in maximal inspiratory pressure after the Olympic distance triathlon was consistent with previous findings after an endurance triathlon (Hill et al., 1991), a marathon race (Chevrolet et al., 1993), and laboratory exercise (Katayama et al., 2012). As it is unlikely that the exercise intensity in these studies was continuously above $85 \% \mathrm{VO}_{2 \max }$, one might suggest that a decrease in inspiratory muscle strength also occurred after long duration and submaximal intensity exercise. Inspiratory—or diaphragmatic - work as evaluated by the duration-intensity exercise product could thus be implicated in the decrease in inspiratory muscle performance. The decrease in transdiaphragmatic pressure and inspiratory muscle strength was due to the fatigue of inspiratory muscles. Romer et al. (2002) defined this fatigue as the incapacity of muscles to develop sufficient contraction force, thus reflecting that the contraction properties of these muscles have been undermined.

The pathophysiological mechanisms that induce inspiratory muscle fatigue nevertheless remain unclear. The main hypotheses concern diaphragmatic cellular lesions (Romer and Polkey, 2008), the ventilatory requirements imposed by the intensity and duration of the exercise (Johnson et al., 1993), and neuromuscular junction dysfunction in the inspiratory muscles (Harms et al., 1998). After respiratory fatigue, a decrement in the alveolar ventilation and an increment in arterial $\mathrm{CO}_{2}$ occur, and the $\mathrm{RM}$ function is then unable to develop sufficient force to produce ventilatory muscle work (Roussos et al., 1979). During high-intensity exercise, the pulmonary load increases. This situation causes RM fatigue that cannot compensate for the tissue $\mathrm{O}_{2}$ demand and the athlete 
then feels respiratory fatigue (Smith et al., 2014). Other mechanisms may also be implicated in the alterations in lung volumes, with a significant effect on inspiratory muscle pressure. For example, we cannot exclude the hypothesis that increases in RV or decreases in FVC were responsible for the decrease in inspiratory muscle pressure (Boussana et al., 2003). Following exercise or $24 \mathrm{hr}$ later, transdiaphragmatic pressure and inspiratory muscle pressure were reported to recover partially or almost completely (Ross et al., 2008). This observation argued for rapidly reversible pathophysiological mechanisms involved in the exercise-induced decrease in maximal inspiratory pressure.

In contrast, Perret et al. (1999) found no decrease in maximal inspiratory pressure after an exhaustive cycling endurance test performed at $85 \% \mathrm{VO}_{2 \max }$ in healthy subjects. This might suggest that, despite an exercise intensity that was reported to induce RM fatigue and exhaustion, the test duration — which was not indicated by the authors-was insufficient to generate a decrease in maximal inspiratory pressure. Several authors have shown a lack of modification in maximal expiratory pressure after endurance exercise (Chevrolet et al., 1993; Ross et al., 2008). In contrast, maximal expiratory pressure was found significantly decreased 20-60 min at the end of the marathon race (Loke et al., 1982). The authors suggested that this decrease was due to a markedly increased and prolonged ventilatory demand requiring inspiratory and expiratory muscle recruitment, particularly from the abdominal muscles. In our study, we measured maximal expiratory pressure (Fig. 1) 3:00 $\pm 0: 30 \mathrm{hr}$ after the triathlon, and this difference in the time at which maximal expiratory pressure was measured might explain this difference.

Decreased RM endurance has been widely observed after strenuous sports activity. An earlier study reported this decrease in endurance as assessed by MVV after a marathon (Loke et al., 1982), and another study noted a significant decrease in $\mathrm{T}_{\text {lim }}$ for inspiratory muscles (26.5\%) 3 days after completion of an ultramarathon (about $87 \mathrm{~km}$ ) performed at $10.2 \mathrm{~km} / \mathrm{hr}$ (Ker and Schultz, 1996). In contrast, Warren et al. (1989) reported no significant modification in MVV during and after a 24-hr ultramarathon performed at $6.3 \mathrm{~km} / \mathrm{hr}$. The authors assumed that the race speed was insufficient to solicit the respiratory apparatus at the level of an intense and short-duration activity. Exercise intensity may thus play a determinant role in RM fatigue (Bender and Martin, 1985). Romer and Polkey (2008) indicated that throughout intense exercise, the level of ventilation sustained by the RM causes fatigue in these muscles. Such RM fatigue could activate the metaboreflex, thus leading to vasoconstriction and a subsequent lack of nutrient sup- ply to muscle and, ultimately, to muscle fatigue, which would limit performance in endurance exercise (Katayama et al., 2012; Wüthrich et al., 2013).

It should also be noted that the degree of fatigue can be influenced by the exercise modality. Hill et al. (1991) and Boussana et al. (2001) observed that cycling involved the participation of thoracic muscles more than diaphragmatic muscle, and this activity has been found to generate greater RM fatigue than running. Indeed, these results indicated that the relative brevity of an Olympic distance triathlon was accompanied by a relatively high intensity of activity, both conditions which would be favorable to high ventilation (Hue et al., 1999), and thus RM fatigue. In addition, the different exercise modalities and successions may have further contributed to the decline in RM performance (Boussana et al., 2001). Effectively, swimming involves the RM for ventilation with an active expiratory phase in the water and an inspiratory phase in combination with arm locomotion, and cycling has been reported to induce RM fatigue because of the crouched position and the increase in abdominal and thoracic impedance (Hill et al., 1991).

The observation of decreased endurance $\mathrm{T}_{\text {lim }}$ (Fig. 3) $24 \mathrm{hr}$ after the race, in contrast to inspiratory muscle strength, raises questions about the pathophysiological mechanisms involved in maximal inspiratory pressure and RM endurance. The pathophysiological phenomena implicated in the decrease in maximal inspiratory pressure may be numerous and recover rapidly after the end of exercise, particularly altered pulmonary volumes (Johnson et al., 1993), bronchoconstriction, decreased pulmonary compliance, peribronchial oedema, and airways obstruction (Zavorsky et al., 2019). In contrast, the decrease in RM endurance has been suggested to result from a decrease in the glycogen reserve in the ventilatory muscles, a mechanism which requires several hours or days to recover completely (Bender and Martin, 1985; Chevrolet et al., 1993).

A consequence of inspiratory muscle fatigue is the reduction in oxygen transport and the amount of circulating blood to the working muscles, thus increasing the fatigue of the peripheral muscles and decreasing performance during endurance exercise (Akınoğlu et al., 2019; Katayama et al., 2012). RM has been reported to be skeletal muscle and morphologically and functionally similar to locomotor muscles (Chevrolet et al., 1993; Romer and Polkey, 2008; Romer et al., 2002). RM training improves wholebody endurance capacity (Verges et al., 2007), whereas RM fatigue may result in the inability to maintain gas and $\mathrm{pH}$ levels within an acceptable range, limiting exercise tolerance (Romer 
and Polkey, 2008). Similarly, Harms et al. (1998) reported an increase in respiratory work during maximal exercise, which induces vasoconstriction in the locomotor muscles and less perfusion to these muscles and $\mathrm{VO}_{2}$. We thus suggest that the persistent decrease in RM endurance on the day following the triathlon could be linked to lower recovery and might limit daily training performance.

We recommend that respiratory function should be monitored throughout the competitive season in triathletes and that specific inspiratory muscle training should be considered during triathlon training sessions. This may be important as it has been demonstrated that RM training increases the amount of time athletes can exercise and improves inspiratory muscle strength and endurance. To this end, it is necessary to set up other studies in order to link the specific training of the RMs and the improvement in sports performances.

Despite the reported limitations of using voluntary tests to measure the performance of RMs, they have now been validated and popularized (Ross et al., 2008). In our study, the athletes were familiar with the tests and motivated; they were also encouraged throughout the measurements. The observed decrease in the performance of the inspiratory muscles cannot be attributed to their lack of motivation. Although we did not measure the partial pressure of $\mathrm{CO}_{2}$, it has been consistently reported no change in previous studies (Gill et al., 2014; Matecki et al., 2001). In conclusion, we have shown that an Olympic distance triathlon causes a decrease in the strength and endurance of inspiratory muscles. Although inspiratory muscle strength recovered rapidly after the race, the persistent reduction in RM endurance 1 day following the triathlon expands the evidence of inspiratory muscle fatigue. However, it raises the questions of whether these are the same mechanisms that are involved in the fatigue of the RMs when it comes to the reduction in strength or endurance of RM, and also whether the fatigue of RMs is a limitation of sports performance.

\section{CONFLICT OF INTEREST}

No potential conflict of interest relevant to this article was reported.

\section{REFERENCES}

Akınoğlu B, Kocahan T, Özkan T. The relationship between peripheral muscle strength and respiratory function and respiratory muscle strength in athletes. J Exerc Rehabil 2019;15:44-49.
American Thoracic Society. Evaluation of impairment/disability secondary to respiratory disorders. Am Rev Respir Dis 1986;133:1205-1209.

Beaver WL, Wasserman K, Whipp BJ. A new method for detecting anaerobic threshold by gas exchange. J Appl Physiol (1985) 1986;60:20202027.

Bender PR, Martin BJ. Maximal ventilation after exhausting exercise. Med Sci Sports Exerc 1985;17:164-167.

Black LF, Hyatt RE. Maximal respiratory pressures: normal values and relationship to age and sex. Am Rev Respir Dis 1969;99:696-702.

Boussana A, Galy O, Hue O, Matecki S, Varray A, Ramonatxo M, Le Gallais $\mathrm{D}$. The effects of prior cycling and a successive run on respiratory muscle performance in triathletes. Int J Sports Med 2003;24:63-70.

Boussana A, Matecki S, Galy O, Hue O, Ramonatxo M, Le Gallais D. The effect of exercise modality on respiratory muscle performance in triathletes. Med Sci Sports Exerc 2001;33:2036-2043.

Chevrolet JC, Tschopp JM, Blanc Y, Rochat T, Junod AF. Alterations in inspiratory and leg muscle force and recovery pattern after a marathon. Med Sci Sports Exerc 1993;25:501-507.

Galy O, Maimoun L, Coste O, Manetta J, Boussana A, Préfaut C, Hue O. Aggravation of pulmonary diffusing capacity in highly trained athletes by 6 weeks of low-volume, low-intensity training. Int J Sports Physiol Perform 2013;8:648-662.

Gill M, Natoli MJ, Vacchiano C, MacLeod DB, Ikeda K, Qin M, Pollock NW, Moon RE, Pieper C, Vann RD. Effects of elevated oxygen and carbon dioxide partial pressures on respiratory function and cognitive performance. J Appl Physiol (1985) 2014;117:406-412.

Harms CA, Wetter TJ, McClaran SR, Pegelow DF, Nickele GA, Nelson WB, Hanson P, Dempsey JA. Effects of respiratory muscle work on cardiac output and its distribution during maximal exercise. J Appl Physiol (1985) 1998;85:609-618.

Hayot M, Ramonatxo M, Matecki S, Milic-Emili J, Prefaut C. Noninvasive assessment of inspiratory muscle function during exercise. Am J Respir Crit Care Med 2000;162:2201-2207.

Hill NS, Jacoby C, Farber HW. Effect of an endurance triathlon on pulmonary function. Med Sci Sports Exerc 1991;23:1260-1264.

Hue O, Le Gallais D, Boussana A, Chollet D, Prefaut C. Ventilatory responses during experimental cycle-run transition in triathletes. Med Sci Sports Exerc 1999;31:1422-1428.

Johnson BD, Babcock MA, Suman OE, Dempsey JA. Exercise-induced diaphragmatic fatigue in healthy humans. J Physiol 1993;460:385-405.

Johnson PH, Cowley AJ, Kinnear WJ. Evaluation of the THRESHOLD trainer for inspiratory muscle endurance training: comparison with the weighted plunger method. Eur Respir J 1996;9:2681-2684.

Katayama K, Iwamoto E, Ishida K, Koike T, Saito M. Inspiratory muscle fatigue increases sympathetic vasomotor outflow and blood pressure 
during submaximal exercise. Am J Physiol Regul Integr Comp Physiol 2012;302:R1167-1175.

Ker JA, Schultz CM. Respiratory muscle fatigue after an ultra-marathon measured as inspiratory task failure. Int J Sports Med 1996;17:493-496.

Koechlin C, Matecki S, Jaber S, Soulier N, Prefaut C, Ramonatxo M. Changes in respiratory muscle endurance during puberty. Pediatr Pulmonol 2005;40:197-204.

Loke J, Mahler DA, Virgulto JA. Respiratory muscle fatigue after marathon running. J Appl Physiol Respir Environ Exerc Physiol 1982;52:821-824.

Matecki S, Topin N, Hayot M, Rivier F, Echenne B, Prefaut C, Ramonatxo M. A standardized method for the evaluation of respiratory muscle endurance in patients with Duchenne muscular dystrophy. Neuromuscul Disord 2001;11:171-177.

Perret C, Pfeiffer R, Boutellier U, Wey HM, Spengler CM. Noninvasive measurement of respiratory muscle performance after exhaustive endurance exercise. Eur Respir J 1999;14:264-269.

Romer LM, McConnell AK, Jones DA. Inspiratory muscle fatigue in trained cyclists: effects of inspiratory muscle training. Med Sci Sports Exerc 2002;34:785-792.

Romer LM, Polkey MI. Exercise-induced respiratory muscle fatigue: implications for performance. J Appl Physiol (1985) 2008;104:879-888.

Ross E, Middleton N, Shave R, George K, Mcconnell A. Changes in respiratory muscle and lung function following marathon running in man. J Sports Sci 2008;26:1295-1301.

Roussos C, Fixley M, Gross D, Macklem PT. Fatigue of inspiratory mus- cles and their synergic behavior. J Appl Physiol Respir Environ Exerc Physiol 1979;46:897-904.

Smith JR, Ade CJ, Broxterman RM, Skutnik BC, Barstow TJ, Wong BJ, Harms $\mathrm{CA}$. Influence of exercise intensity on respiratory muscle fatigue and brachial artery blood flow during cycling exercise. Eur J Appl Physiol 2014;114:1767-1777.

Tiller NB, Turner LA, Taylor BJ. Pulmonary and respiratory muscle function in response to 10 marathons in 10 days. Eur J Appl Physiol 2019; 119:509-518.

Verges S, Sager Y, Erni C, Spengler CM. Expiratory muscle fatigue impairs exercise performance. Eur J Appl Physiol 2007;101:225-232.

Walker DJ, Walterspacher S, Schlager D, Ertl T, Roecker K, Windisch W, Kabitz HJ. Characteristics of diaphragmatic fatigue during exhaustive exercise until task failure. Respir Physiol Neurobiol 2011;176:14-20.

Warren GL, Cureton KJ, Sparling PB. Does lung function limit performance in a 24-hour ultramarathon? Respir Physiol 1989;78:253-263.

Wüthrich TU, Notter DA, Spengler CM. Effect of inspiratory muscle fatigue on exercise performance taking into account the fatigue-induced excess respiratory drive. Exp Physiol 2013;98:1705-1717.

Zavorsky GS, Zimmerman RD, Shendell DG, Goodfellow LT. Acute reduction in spirometry values after prolonged exercise among recreational runners. Respir Care 2019;64:26-33.

Zocchi L, Fitting JW, Majani U, Fracchia C, Rampulla C, Grassino A. Effect of pressure and timing of contraction on human rib cage muscle fatigue. Am Rev Respir Dis 1993;147:857-864. 